\title{
A CLOUD MIGRATION DECISION SUPPORT SYSTEM FOR SMES IN TAMIL NADU (INDIA) USING AHP
}

\begin{abstract}
Cloud computing is a new computing paradigm which has the potential to speed up Information Technology (IT) adoption among SMEs in developing economies. Its successful implementation can present SMEs with various benefits like reduced IT costs, high scalability and faster time to market. In recent years, many research have been carried in both academia and in businesses to explain the features, benefits and risks of cloud adoption. Literature review reveals that there are existing frameworks available to support cloud migration. However, there is very little literature available to support cloud migration decisions, which covers the whole cloud migration process for SMEs in Tamil Nadu. This paper aims to fill that gap by presenting the SME decision makers (DMs) with a decision support tool. The proposed cloud migration decision support system (CMDSS) will be based on Analytical Hierarchy Process (AHP) and will aid decision makers to make cloud migration decision effectively by suggesting a path from where to start, to how to complete the migration.
\end{abstract}

Keywords: cloud migration, IT adoption, DSS, AHP

\section{Introduction}

This study focuses on SMEs in Tamil Nadu, southern state of the Indian Union with a population of 72 million. Tamil Nadu accounts for 689,000 registered SMEs, which is the largest in the whole of the Indian Union.

Indian SME sector are traditionally laggards in technology adoption. According to (Iyer et.al 2013), there are two main reasons for SMEs to be laggards for adopting a new technology. The first reason is purely the workforce or management resistance to move from human resource driven manual process to system driven automated process. The second reason being the high capital investment required to have the whole enterprise IT set up and running. Iyer et.al (2013) argues that "cloud is the elixir the SMEs looking out for" due to the pay per usage model offered by cloud. However, migrating to a cloud environment is not straightforward and involves many risks and challenges and therefore, SME decision makers need to be aware of the benefits and risks of a cloud migration.

Several frameworks have been developed in recent years, which can be used by decision makers as a guide for cloud adoption. However, there are no tools available for DM to support cloud adoption decisions. In this paper, we propose a CMDSS for SMEs in Tamil Nadu based on the Analytical Hierarchy Process (AHP).

\section{Literature Review}

The following three frameworks to support cloud adoption decisions follow multi criteria decision-making approach and can be considered basis for the AHP model used in the proposed CMDSS.

The framework by Garg, Versteeg and Buyya (2013) is based on AHP and can be used to rank services offered by different cloud computing providers. A tool based on their model is available that can be used by DMs to compare services offered by different providers to find out which one could be more suitable for the business. (Andrikopoulos, Strauch, and 
ISAHP Article: A cloud migration decision support system for SMEs in Tamil Nadu (India) using AHP To Be Submitted to the International Symposium of the Analytic Hierarchy Process 2016, London, U.K.

Frank Leymann 2013) have proposed a framework based on ANP to support application migration to a cloud environment. A prototypical implementation of their framework helps DMs understand the different tasks involved in cloud migration. (Saripalli and Pingali 2011) have proposed a theoretical framework based on Multi Attribute Decision Making (MADM). In this framework, they have used simple additive weighting to calculate the value of each attribute.

\section{Objectives}

This study has two main objectives. Firstly, to investigate and analyse the cloud adoption decision factors for SMEs in Tamil Nadu. Secondly, to develop a DSS for cloud migration for SMEs in Tamil Nadu incorporating the factors identified in the study.

\section{Research Design/Methodology}

The cloud adoption decisions will the goal of the system and the criteria and alternatives used will be based on hierarchy used by (Saripalli and Pingali, 2011) in their decision methodology. To identify the sub criteria relevant to the target population (SMEs in Tamil $\mathrm{Nadu}$ ), a questionnaire survey method among SME decision makers in Tamil Nadu is used. The proposed CMDSS will utilise the AHP model to suggest the best alternative for the DM. Based on the AHP hierarchy, a DSS will be developed and will be given as a tool to SME decision makers for evaluation. We will follow evolutionary prototyping as the design methodology for the development of DSS.

\section{Data/Model Analysis}

An AHP model developed for cloud adoption is shown in figure 1. To identify the subcriteria a questionnaire survey is planned and depending upon the results of the survey, the sub-criteria will be added to the AHP model. A pilot study has already been conducted among 14 DMs. Based on the results, the questionnaire for the main study has been designed and the main study is planned to be conducted.

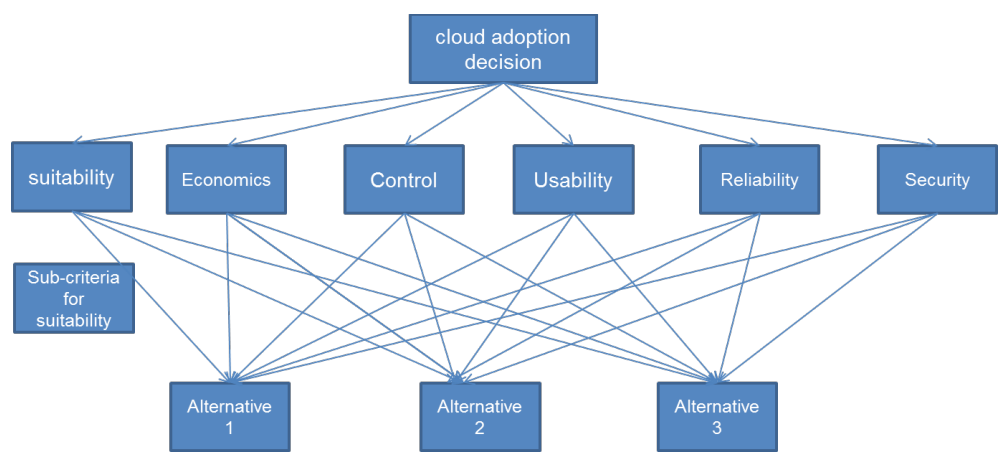

Figure 1: AHP hierarchy for cloud adoption

This study is part of an ongoing research approved by Sheffield Hallam University.

\section{Conclusions}

This research adds theoretical and practical contributions and provides guidance for future research related to cloud migration in India and possibly SMEs in other developing economies like India. The main contribution to the body of knowledge is creating empirical evidence of the determinants of cloud adoption among SMEs in Tamil Nadu. The development of CMDSS will be the practical contribution of this research.

\section{Key References}


ISAHP Article: A cloud migration decision support system for SMEs in Tamil Nadu (India) using AHP To Be Submitted to the International Symposium of the Analytic Hierarchy Process 2016, London, U.K.

ANDRIKOPOULOS, Vasilios, STRAUCH, Steve and LEYMANN, Frank (2013). Decision Support for Application Migration to the Cloud. Proceedings of CLOSER'13, , 149-155.

ARIPALLI, Prasad and PINGALI, Gopal (2011). MADMAC: Multiple attribute decision methodology for adoption of clouds. In: Cloud computing (CLOUD), 2011 IEEE international conference on, IEEE, 316-323.

DARSOW, Alexander (2014). Decision support for application migration to the cloud.

GARG, Saurabh Kumar, VERSTEEG, Steve and BUYYA, Rajkumar (2013). A framework for ranking of cloud computing services. Future generation computer systems, 29 (4), 1012-1023.

IYER, Easwar K., et al. (2013). Decision variables influencing Cloud adoption by SME sector: A Conjoint Analysis Mapping. In: National conference on business analytics \& business intelligence, 